\title{
A Risk Tertiles Model for Predicting Mortality in Patients With Acute Respiratory Distress Syndrome: Age, Plateau Pressure, and $\mathrm{P}_{\mathrm{aO}_{2}} / \mathrm{F}_{\mathrm{IO}_{2}}$ at ARDS Onset Can Predict Mortality
}

\author{
Jesús Villar MD PhD, Lina Pérez-Méndez MD PhD, Santiago Basaldúa MSc, \\ Jesús Blanco MD PhD, Gerardo Aguilar MD, Darío Toral MD, Elizabeth Zavala MD PhD, \\ Miguel A Romera MD, Gumersindo González-Díaz MD PhD, Frutos del Nogal MD, \\ Antonio Santos-Bouza MD PhD, Luís Ramos MD, Santiago Macías MD, and \\ Robert M Kacmarek PhD RRT FAARC; Hospitales Españoles Para el Estudio de la Lesión \\ Pulmonar (HELP) Network ${ }^{*}$
}

\begin{abstract}
BACKGROUND: Predicting mortality has become a necessary step for selecting patients for clinical trials and defining outcomes. We examined whether stratification by tertiles of respiratory and ventilatory variables at the onset of acute respiratory distress syndrome (ARDS) identifies patients with different risks of death in the intensive care unit. METHODS: We performed a secondary analysis of data from 220 patients included in 2 multicenter prospective independent trials of ARDS patients mechanically ventilated with a lung-protective strategy. Using demographic, pulmonary, and ventilation data collected at ARDS onset, we derived and validated a simple prediction model based on a population-based stratification of variable values into low, middle, and high tertiles. The derivation cohort included 170 patients (all from one trial) and the validation cohort included 50 patients (all from a second trial). RESULTS: Tertile distribution for age, plateau airway pressure $\left(\mathrm{P}_{\text {plat }}\right)$, and $\mathrm{P}_{\mathrm{aO}} / \mathrm{F}_{\mathrm{IO}_{2}}$ at ARDS onset identified subgroups with different mortalities, particularly for the highest-risk tertiles: age ( $>62$ years), $\mathrm{P}_{\text {plat }}(>29 \mathrm{~cm} \mathrm{H} \mathrm{O})$, and $\mathrm{P}_{\mathrm{aO}}{ }_{2} / \mathrm{F}_{\mathrm{IO}_{2}}(<112 \mathrm{~mm} \mathrm{Hg})$. Risk was defined by the number of coexisting high-risk tertiles: patients with no high-risk tertiles had a mortality of $12 \%$, whereas patients with 3 high-risk tertiles had $90 \%$ mortality $(P<.001)$. CONCLUSIONS: A prediction model based on tertiles of patient age, $\mathrm{P}_{\text {plat }}$, and $\mathrm{P}_{\mathrm{aO}}{ }_{2} / \mathrm{F}_{\mathrm{IO}_{2}}$ at the time the patient meets ARDS criteria identifies patients with the lowest and highest risk of intensive care unit death. Key words: acute respiratory distress syndrome; $A R D S$; age; mortality; $P_{a O} / F_{I O} ;$ plateau airway pressure; prediction; tertiles. [Respir Care 2011;56(4):420-428. (C) 2011 Daedalus Enterprises]
\end{abstract}

\section{Introduction}

Various attempts have been made to predict which patients with acute respiratory distress syndrome (ARDS) are likely to have an unfavorable outcome. ${ }^{1-5}$ Associations between indicators of illness severity and mortality have been reported, but their predictive power remains controversial. $^{2-11}$ Observational studies of ARDS patients have had variable findings, but in general, the prognosis seems to be related to age, underlying disease, severity of lung damage, and extrapulmonary organ dysfunction. ${ }^{3,4,6,11-14}$ A joint American-European Consensus Conference formalized the criteria for diagnosing acute lung injury (ALI) and ARDS, ${ }^{15}$ but no 2 single large ${ }^{2-5,11}$ or small ${ }^{7-10}$ epide- miological studies that used the American-European Consensus Conference ARDS definition found the same mortality predictors. Many of those studies used median or mean values of selected variables collected during the ARDS disease process and multivariable regression anal-

See the Related Editorial on Page 533

ysis to analyze the associations between those variables and ARDS outcomes, including death. Although reductionism to a mean or median value is useful, it can lead to loss of important information about the whole population, as was shown in a recent meta-analysis on the benefits of 
antidepressant medications. That meta-analysis included 5,133 patients in 35 randomized controlled trials in which the use of mean or median values gave a poor description of outcome. ${ }^{16}$

We analyzed data from a prospective multicenter study of patients who met the American-European Consensus Conference ARDS definition and were mechanically ventilated with a lung-protective ventilation strategy. Previously we assessed whether a systematic method, namely a fixed standard ventilation setting, identifies patients with persistent ARDS, and those results were published elsewhere. ${ }^{17}$ In the present study we explored whether selected

Jesús Villar MD PhD, Lina Pérez-Méndez MD PhD, Jesús Blanco MD $\mathrm{PhD}$, and Elizabeth Zavala MD PhD are affiliated with Centro de Investigación Biomédica en Red (CIBER) de Enfermedades Respiratorias, Instituto de Salud Carlos III, Madrid, Spain. Dr Villar is also affiliated with the Research Unit, Multidisciplinary Organ Dysfunction Evaluation Research Network, Hospital Universitario Dr Negrin, Las Palmas de Gran Canaria, Spain. Dr Blanco is also affiliated with the Intensive Care Unit, Hospital Universitario Rio Hortega, Valladolid, Spain. Lina PérezMéndez MD PhD and Santiago Basaldúa MSc are affiliated with the Research Unit, Hospital Universitario Nuestra Señora de Candelaria, Tenerife, Spain. Gerardo Aguilar MD is affiliated with the Department of Anesthesiology, Hospital Clínico de Valencia, Valencia, Spain. Darío Toral MD is affiliated with the Intensive Care Unit, Hospital Universitario 12 de Octubre, Madrid, Spain. Elizabeth Zavala MD PhD is affiliated with the Department of Anesthesia, Hospital Clinic, Barcelona, Spain. Miguel A Romera MD is affiliated with the Intensive Care Unit, Hospital Universitario Puerta de Hierro, Madrid, Spain. Gumersindo González-Díaz MD PhD is affiliated with the Intensive Care Unit, Hospital Universitario Morales Meseguer, Murcia, Spain. Frutos del Nogal MD is affiliated with the Intensive Care Unit, Hospital Universitario Severo Ochoa, Madrid, Spain. Antonio Santos-Bouza MD PhD is affiliated with the Intensive Care Unit, Hospitales Universitarios de Santiago, Santiago de Compostela, Spain. Luís Ramos MD is affiliated with the Intensive Care Unit, Hospital General de La Palma, La Palma, Canary Islands, Spain. Santiago Macías MD is affiliated with the Intensive Care Unit, Hospital General de Segovia, Segovia, Spain. Robert M Kacmarek $\mathrm{PhD}$ RRT FAARC is affiliated with the Respiratory Care Department, Massachusetts General Hospital, and the Department of Anesthesia, Harvard University, Boston, Massachusetts.

This research was partly supported in part by grant 07/0113 from Fondo de Investigación Sanitaria, Madrid, Spain, and by the Asociación Científica Pulmón y Ventilación Mecánica, Las Palmas, Spain.

To avoid potential conflict of interest, Editor in Chief Dean R Hess was blinded to the peer review process, deferring to Deputy Editor Richard D Branson MSc.

* Members of the Hospitales Españoles Para el Estudio de la Lesión Pulmonar (HELP) Network are listed in the supplementary materials at http://www.rcjournal.com.

Correspondence: Jesús Villar MD PhD, Multidisciplinary Organ Dysfunction Evaluation Research Network, Hospital Universitario Dr Negrin Barranco de la Ballena, s/n 4th Floor, South Wing, 35010 Las Palmas de Gran Canaria, Canary Islands, Spain. E-mail: jesus.villar54@gmail.com.

DOI: $10.4187 /$ respcare.00811 respiratory, ventilation, and physiological variables at the time the patients met the ARDS definition were associated with intensive care unit (ICU) mortality, independent of the underlying disease or specific therapy. Our assessment of established ARDS after a PEEP/F $\mathrm{IO}_{2}$ trial was described elsewhere, ${ }^{17}$ but none of the outcome data reported in the present study have been published.

We hypothesized that tertile stratification of values of clinical variables, collected at the time the patients meet the American-European Consensus Conference ARDS criteria, would identify patients at greater risk of ICU death.

\section{Methods}

This study was approved by the Ethics Committee for Clinical Research at Hospital Universitario Nuestra Señora de Candelaria, Tenerife, Spain, the Hospital Universitario Río Hortega, Valladolid, Spain, and the local institutional review boards of all the participating hospitals.

\section{Study Population}

We performed a secondary analysis of data from 2 independent multicenter trials of ARDS patients ventilated with a lung-protective ventilation strategy. For the model derivation population, data were drawn from the Hospitales Españoles Para el Estudio de la Lesión Pulmonar (HELP) study database. ${ }^{17} \mathrm{We}$ analyzed only patients who developed ARDS. The database comprised 170 ARDS patients admitted into the HELP network of ICUs. All consecutive patients age $>18$ years and who met the American-European Consensus Conference ARDS criteria ${ }^{15}$ were screened for enrollment, regardless of their current status or medical history. We excluded only patients with brain death, terminal-stage cancer, or a do-not-resuscitate order. The validation cohort consisted of 50 patients with established ARDS in the low-tidal-volume (low- $\mathrm{V}_{\mathrm{T}}$, $5-8 \mathrm{~mL} / \mathrm{kg}$ predicted body weight) arm of the Acute Respiratory Insufficiency España Study (ARIES study), by our group. ${ }^{18}$ Our validation cohort also had the data obtained at the time the patients initially met the AmericanEuropean Consensus Conference ARDS criteria.

\section{Study Design}

We examined whether it is possible to assess and quantify the risk of death in ARDS patients at the onset of ARDS (at the time the patients meet ARDS criteria), independent of their disease process or response to treatment, provided they were ventilated with a lung-protective strategy. Patients were screened daily, and data were recorded with standardized forms. We recorded demographic data (eg, age, sex); cause of ARDS (eg, sepsis, pneumonia, multiple trauma, aspiration); timing of ARDS (ICU days 
before meeting the ARDS definition); respiratory physiology $\left(\mathrm{P}_{\mathrm{aO}_{2}} / \mathrm{F}_{\mathrm{IO}_{2}}, \mathrm{P}_{\mathrm{aCO}_{2}}, \mathrm{pH}\right.$, respiratory-system compliance); and mechanical ventilation data $\left(\mathrm{F}_{\mathrm{IO}_{2}}, \mathrm{~V}_{\mathrm{T}}\right.$, respiratory rate, PEEP, plateau airway pressure $\left[\mathrm{P}_{\text {plat }}\right]$ ) at the time of ARDS onset, before considering changing the ventilator settings. We also recorded Acute Physiology and Chronic Health Evaluation (APACHE II) score during the first 24 hours in the ICU ${ }^{19}$ and Lung Injury Severity Score ${ }^{20}$ at the time the patient met the ARDS definition. We also recorded the occurrence of shock and number of organ failures included in the Sequential Organ Failure Assessment scale ${ }^{21}$ at baseline, ICU and hospital stay, and ICU mortality. All patients were mechanically ventilated. For ventilator management we recommended a $V_{T}$ of $5-9 \mathrm{~mL} / \mathrm{kg}$ predicted body weight, a respiratory rate that maintained adequate $\mathrm{P}_{\mathrm{aCO}}$, and PEEP and $\mathrm{F}_{\mathrm{IO}_{2}}$ that maintained $\mathrm{P}_{\mathrm{aO}_{2}}>60 \mathrm{~mm} \mathrm{Hg}$ or $\mathrm{S}_{\mathrm{pO}_{2}}>90 \%$. None of the patients in this cohort received activated protein $\mathrm{C}$ or corticosteroids as an adjunctive treatment.

\section{Statistical Analysis}

For the power calculations for the derivation cohort we estimated an absolute $20 \%$ mortality-rate reduction, alpha $=.05$ and power goal $=0.80$. Since there are no previous studies on tertile stratification in ARDS patients, we studied various group-size scenarios with cohorts of 132 to 168 patients. The population size of our derivation cohort satisfied all scenarios.

Data are reported as percentages or mean \pm SD unless otherwise specified. We compared continuous variables with the Student $t$ test. We used the Mann-Whitney U rank test for variables with non-normal distribution. We compared categorical variables with the chi-square and Fisher exact tests. We stratified the derivation cohort values into low, middle, and high risk tertiles, with approximately equal numbers of patients. Since no data on tertiles have been previously reported in the ARDS literature, we did not choose any pre-selected cutoff points for tertiles; instead, the tertile ranges were based on the distribution of each variable in the derivation cohort. Specifically, we listed in sequential order the actual values of each variable for all 170 patients and divided them into 3 equal groups. We performed a univariate analysis of each variable, categorized by its tertiles, as a predictor of outcome. We used the chi-square statistic (displayed as $P$ for trends) to determine the overall significance of each independent association between the variable and the outcome. We also calculated the relative risk of death and $95 \%$ confidence intervals associated with each tertile with the Jeffrey interval for a binomial proportion.

Once we had determined the ICU mortality associated with each tertile range, we identified the variables that could be used as regressors, based on the $P$ values. We tested for linear trends across tertiles using the tertile with the lowest mortality as the reference group and considering the tertile as an ordinal variable. We deemed the tertiles associated with the highest mortality as risk factors for ARDS death. We aimed to develop a simple score based on the number of high-risk tertiles to identify patients with the best and worst outcomes. Then we analyzed the cross-tabulated groups with the chi-square test.

To assess the internal validity of our model, we adjusted for multiple comparisons with the Monte-Carlo simulation test, with multiple comparisons extracted from the database. $^{22,23} \mathrm{We}$ assessed external validation by applying our model to an independent patient population, and tested with the maximum-likelihood chi-square test. ${ }^{24,25}$ We evaluated the model discrimination in the derivation and validation cohorts with the area under the receiver operating characteristic curve ${ }^{26}$ and compared the overall performance of our model to that of APACHE II score. All analyses were performed with statistics software (SPSS 15.0, SPSS, Chicago, Illinois). We considered a 2 -sided $P$ value $<.05$ statistically significant.

\section{Results}

On average, the 170 patients in the derivation cohort met the American-European Consensus Conference ARDS criteria at $2.4 \pm 3.0$ days after ICU admission. The overall ICU mortality was $34 \%$. None of the primary ARDS risk factors was significantly associated with ICU outcome. In general, patients who died were older, had higher APACHE II score, and stayed more days in the ICU before ARDS onset than did survivors. The mean respiratory and ventilation variables showed no statistically significant differences between the survivors and non-survivors (Table 1).

We divided the data into tertiles (Table 2). Applied PEEP at study entry was the only variable that could not be distributed with a comparable number of cases in each tertile. The applied PEEP at ARDS onset was mostly (and unevenly) distributed at the PEEP levels $5 \mathrm{~cm} \mathrm{H}_{2} \mathrm{O}(n=24)$, $8 \mathrm{~cm} \mathrm{H}_{2} \mathrm{O}(n=37), 10 \mathrm{~cm} \mathrm{H}_{2} \mathrm{O}(n=44)$, and $12 \mathrm{~cm} \mathrm{H}_{2} \mathrm{O}$ $(n=20)$. Despite the lack of comparable tertile sizes for PEEP, a re-analysis of their distribution showed that the best associations between increasing PEEP level at the time of ARDS onset and increasing ICU mortality were PEEP $<8 \mathrm{~cm} \mathrm{H}_{2} \mathrm{O}(n=46)$, PEEP $8-9 \mathrm{~cm} \mathrm{H}_{2} \mathrm{O}(n=41)$, and PEEP $\geq 10 \mathrm{~cm} \mathrm{H}_{2} \mathrm{O}(n=83)$, although this trend did not reach statistical significance $(P=.11)$ (Table 3$)$. The tertile distribution for the other variables at ARDS onset identified patients with a wide range of ICU mortality risk, although only the tertile distribution for $\mathrm{P}_{\text {plat }}$ and $\mathrm{P}_{\mathrm{aO}_{2}} / \mathrm{F}_{\mathrm{IO}_{2}}$ reached statistical significance (see Table 3).

Subjects in the tertiles age $>62$ years, $\mathrm{P}_{\text {plat }}>29 \mathrm{~cm} \mathrm{H}_{2} \mathrm{O}$, and $\mathrm{P}_{\mathrm{aO}_{2}} / \mathrm{F}_{\mathrm{IO}_{2}}<112 \mathrm{~mm} \mathrm{Hg}$ had significantly higher ICU mortality than the patients in the other 2 tertiles for each variable. The relative risk of death, for comparison of the 
Table 1. Derivation Cohort at Study Entry*

\begin{tabular}{|c|c|c|c|}
\hline & $\begin{array}{l}\text { Survivors } \\
(\mathrm{n}=113)\end{array}$ & $\begin{array}{l}\text { Non-Survivors } \\
\quad(\mathrm{n}=57)\end{array}$ & $P$ \\
\hline Male $(\%)$ & 69 & 31 & .31 \\
\hline Age $($ mean $\pm \mathrm{SD}$ y) & $48 \pm 18$ & $58 \pm 18$ & .001 \\
\hline \multicolumn{4}{|l|}{ Main Diagnosis and Disease Severity } \\
\hline Sepsis, no. (\%) & $29(26)$ & $20(35)$ & .20 \\
\hline Pneumonia, no. (\%) & $34(30)$ & $12(21)$ & .20 \\
\hline Multiple trauma, no. $(\%)$ & $23(20)$ & $7(12)$ & .19 \\
\hline Aspiration, no. (\%) & $17(15)$ & $11(19)$ & .48 \\
\hline APACHE II (mean \pm SD) & $19 \pm 7$ & $23 \pm 5$ & .002 \\
\hline Lung Injury Severity Score (mean \pm SD) & $2.6 \pm 0.7$ & $2.9 \pm 0.4$ & .12 \\
\hline Days in ICU before meeting ARDS criteria (mean \pm SD) & $2.0 \pm 2.8$ & $3.0 \pm 3.2$ & .048 \\
\hline \multicolumn{4}{|l|}{ Physiologic Variables (mean \pm SD) } \\
\hline $\mathrm{pH}$ & $7.32 \pm 0.11$ & $7.33 \pm 0.11$ & .87 \\
\hline $\mathrm{P}_{\mathrm{aCO}_{2}}(\mathrm{~mm} \mathrm{Hg})$ & $43 \pm 13$ & $45 \pm 11$ & .40 \\
\hline $\mathrm{P}_{\mathrm{aO}_{2}} / \mathrm{F}_{\mathrm{IO}_{2}}(\mathrm{~mm} \mathrm{Hg})$ & $131 \pm 32$ & $125 \pm 36$ & .28 \\
\hline Respiratory-system compliance $\dagger\left(\mathrm{mL} / \mathrm{cm} \mathrm{H}_{2} \mathrm{O}\right)$ & $32 \pm 12$ & $30 \pm 12$ & .33 \\
\hline \multicolumn{4}{|l|}{ Ventilation Variables (mean $\pm \mathrm{SD})$} \\
\hline $\mathrm{V}_{\mathrm{T}}(\mathrm{mL} / \mathrm{kg}$ predicted body weight $)$ & $7.8 \pm 1.6$ & $7.5 \pm 1.7$ & .16 \\
\hline $\mathrm{F}_{\mathrm{IO}_{2}}$ & $0.63 \pm 0.17$ & $0.67 \pm 0.19$ & .13 \\
\hline Respiratory rate (breaths/min) & $19 \pm 6$ & $21 \pm 5$ & .08 \\
\hline $\operatorname{PEEP}\left(\mathrm{cm} \mathrm{H}_{2} \mathrm{O}\right)$ & $8.7 \pm 3.5$ & $9.5 \pm 3.0$ & .39 \\
\hline Plateau airway pressure $\left(\mathrm{cm} \mathrm{H}_{2} \mathrm{O}\right)$ & $26 \pm 6$ & $28 \pm 6$ & .08 \\
\hline \multicolumn{4}{|l|}{ Shock and Organ Failure } \\
\hline Number of organ failures (mean $\pm \mathrm{SD}$ ) & $1.1 \pm 1.0$ & $1.1 \pm 1.1$ & .92 \\
\hline Shock, no. $(\%)$ & $45(40)$ & $22(39)$ & .88 \\
\hline
\end{tabular}

Table 2. Derivation Cohort Overall and Tertile Distribution of Demographics and Selected Respiratory Physiology and Ventilation Variables*

\begin{tabular}{|c|c|c|c|c|}
\hline & Mean $\pm \mathrm{SD}$ & Low-Risk Tertile & Medium-Risk Tertile & High-Risk Tertile \\
\hline Age $(y)$ & $51 \pm 18$ & $<45$ & $45-62$ & $>62$ \\
\hline $\mathrm{V}_{\mathrm{T}}(\mathrm{mL} / \mathrm{kg}$ predicted body weight $)$ & $7.7 \pm 1.6$ & $<6.8$ & $6.8-7.7$ & $>7.7$ \\
\hline Respiratory rate (breaths/min) & $20 \pm 6$ & $<16$ & $16-22$ & $>22$ \\
\hline $\operatorname{PEEP}\left(\mathrm{cm} \mathrm{H}_{2} \mathrm{O}\right)$ & $9 \pm 3$ & $<8$ & $8-9$ & $\geq 10$ \\
\hline Plateau airway pressure $\left(\mathrm{cm} \mathrm{H}_{2} \mathrm{O}\right)$ & $26 \pm 6$ & $<25$ & $25-29$ & $>29$ \\
\hline Respiratory-system compliance $\dagger\left(\mathrm{mL} / \mathrm{cm} \mathrm{H}_{2} \mathrm{O}\right)$ & $32 \pm 12$ & $>34$ & $26-34$ & $<26$ \\
\hline $\mathrm{F}_{\mathrm{IO}_{2}}$ & $0.65 \pm 0.2$ & $<0.5$ & $0.5-0.6$ & $>0.6$ \\
\hline $\mathrm{P}_{\mathrm{aO}_{2}} / \mathrm{F}_{\mathrm{IO}_{2}}(\mathrm{~mm} \mathrm{Hg})$ & $129 \pm 33$ & $>142$ & $112-142$ & $<112$ \\
\hline $\mathrm{P}_{\mathrm{aCO}_{2}}(\mathrm{~mm} \mathrm{Hg})$ & $44 \pm 12$ & $<38$ & $38-45$ & $>45$ \\
\hline $\mathrm{pH}$ & $7.32 \pm 0.11$ & $>7.40$ & $7.30-7.40$ & $<7.30$ \\
\hline Number of organ failures & $1.1 \pm 1.0$ & 0 & 1 & $>1$ \\
\hline
\end{tabular}

patients in the highest-risk tertile and those in the lowest tertile at study entry was $2.5(95 \%$ CI 1.4-4.5) for age, 2.4 (95\% CI 1.8-3.3) for $\mathrm{P}_{\text {plat }}$, and $1.59(1.0-2.6)$ for $\mathrm{P}_{\mathrm{aO}_{2}} / \mathrm{F}_{\mathrm{IO}_{2}}$ (see Table 3 ). Each of those 3 variables correlated independently with ARDS outcome. When considering only age, $\mathrm{P}_{\text {plat }}$, and $\mathrm{P}_{\mathrm{aO}_{2}} / \mathrm{F}_{\mathrm{IO}_{2}}$, we found large differences in the mortality risk across the 4 possibilities for increasing presence of highest-risk tertiles (ie, none, 1, 2, or 3 highest-risk tertiles) (Fig. 1). The 50 patients with no highest-risk tertiles had a $12 \%$ mortality rate $(95 \%$ CI 6-21\%). The 79 
A Risk Tertiles Model for Predicting Mortality in ARDS Patients

Table 3. Derivation Cohort Tertile Distribution and Mortality*

\begin{tabular}{|c|c|c|c|c|c|}
\hline & $\begin{array}{c}\text { Number of } \\
\text { Highest-Risk Tertiles }\end{array}$ & $\begin{array}{l}\text { Mortality } \\
(\%)\end{array}$ & $\begin{array}{l}\text { Relative } \\
\text { Risk }\end{array}$ & $\begin{array}{c}95 \% \text { CI of } \\
\text { Relative Risk }\end{array}$ & $P$ for Trends $\dagger$ \\
\hline \multirow[t]{4}{*}{ Age } & & & & & .001 \\
\hline & 1 & 19 & 1.0 & NA & \\
\hline & 2 & 33 & 1.7 & $0.9-3.3$ & \\
\hline & 3 & 48 & 2.5 & $1.4-4.5$ & \\
\hline \multirow[t]{4}{*}{$\mathrm{V}_{\mathrm{T}}$} & & & & & .54 \\
\hline & 1 & 35 & 1.0 & NA & \\
\hline & 2 & 34 & 1.0 & $0.6-1.6$ & \\
\hline & 3 & 30 & 0.8 & $0.5-1.5$ & \\
\hline \multirow[t]{4}{*}{ Respiratory rate } & & & & & .11 \\
\hline & 1 & 27 & 1.0 & NA & \\
\hline & 2 & 31 & 1.2 & $0.7-2.1$ & \\
\hline & 3 & 42 & 1.6 & $0.9-2.7$ & \\
\hline \multirow[t]{4}{*}{ Plateau airway pressure } & & & & & $<.001$ \\
\hline & 1 & 23 & 1.0 & NA & \\
\hline & 2 & 23 & 1.0 & $0.7-1.5$ & \\
\hline & 3 & 54 & 2.4 & $1.8-3.3$ & \\
\hline \multirow[t]{4}{*}{ PEEP } & & & & & .11 \\
\hline & 1 & 22 & 1.0 & NA & \\
\hline & 2 & 34 & 1.4 & $0.7-2.8$ & \\
\hline & 3 & 40 & 1.7 & $1.1-3.2$ & \\
\hline \multirow[t]{4}{*}{ Respiratory-system compliance } & & & & & .15 \\
\hline & 1 & 25 & 1.0 & NA & \\
\hline & 2 & 29 & 1.1 & $0.6-2.3$ & \\
\hline & 3 & 40 & 1.6 & $0.8-3.1$ & \\
\hline \multirow[t]{4}{*}{$\mathrm{F}_{\mathrm{IO}_{2}}$} & & & & & .28 \\
\hline & 1 & 31 & 1.0 & NA & \\
\hline & 2 & 29 & 1.0 & $0.5-1.7$ & \\
\hline & 3 & 40 & 1.3 & $0.8-2.1$ & \\
\hline \multirow[t]{4}{*}{$\mathrm{P}_{\mathrm{aO}_{2}} / \mathrm{F}_{\mathrm{IO}_{2}}$} & & & & & .02 \\
\hline & 1 & 30 & 1.0 & NA & \\
\hline & 2 & 23 & 0.9 & $0.5-1.5$ & \\
\hline & 3 & 47 & 1.6 & $1.0-2.6$ & \\
\hline \multirow[t]{4}{*}{$\mathrm{P}_{\mathrm{aCO}}$} & & & & & .58 \\
\hline & 1 & 30 & 1.0 & NA & \\
\hline & 2 & 35 & 1.2 & $0.7-2.0$ & \\
\hline & 3 & 35 & 1.2 & $0.7-2.0$ & \\
\hline \multirow[t]{4}{*}{$\mathrm{pH}$} & & & & & .54 \\
\hline & 1 & 36 & 1.0 & NA & \\
\hline & 2 & 36 & 1.0 & $0.6-1.7$ & \\
\hline & 3 & 30 & 0.8 & $0.5-1.5$ & \\
\hline \multirow[t]{4}{*}{ Number of organ failures } & & & & & .84 \\
\hline & 1 & 34 & 1.0 & NA & \\
\hline & 2 & 33 & 1.0 & $0.6-1.6$ & \\
\hline & 3 & 33 & 1.0 & $0.6-1.6$ & \\
\hline $\begin{array}{l}\text { * At study entry: } 170 \text { intensive care unit pa } \\
\dagger \text { Via chi-square } \\
\text { NA = not applicable }\end{array}$ & et the American-European C & nference defi & te respiratory & drome (ARDS). & \\
\hline
\end{tabular}

patients with only one highest-risk tertile had a $33 \%$ mortality rate $(95 \%$ CI $25-42 \%$, relative risk 2.7 , 95\% CI $1.8-4.5)$. The 31 patients with 2 highest-risk tertiles had a $52 \%$ mortality rate $(95 \%$ CI $37-66 \%$, relative risk 4.3 , 95\% CI 2.8-7.0). The 10 patients with all 3 highest-risk tertiles had a $90 \%$ mortality rate $(95 \%$ CI 67-98\%, relative risk 7.5, 95\% CI 4.9-11.5) $(P<.001)$. The log odds ratios describing the effect of being in the highest-risk tertile for age, $\mathrm{P}_{\text {plat }}$, and $\mathrm{P}_{\mathrm{aO}_{2}} / \mathrm{F}_{\mathrm{IO}_{2}}$ versus being in the other 2 tertiles were $0.58,0.86$, and 0.58 , respectively. 


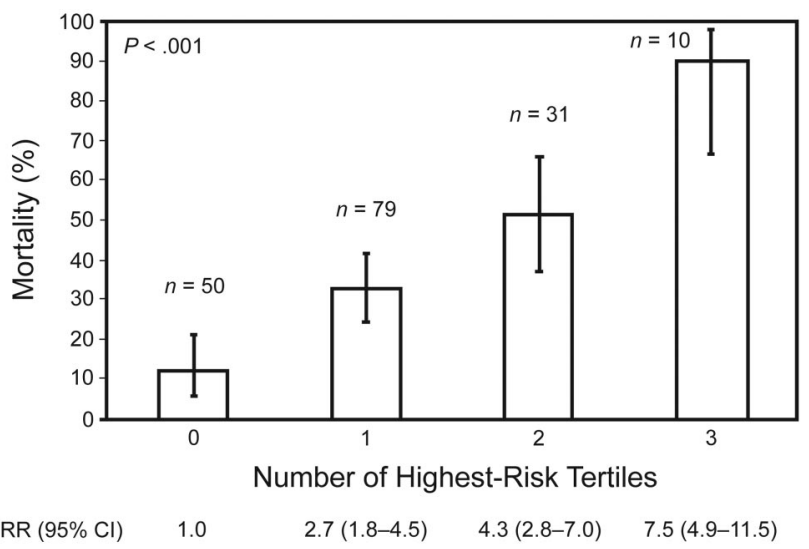

Fig. 1. Risk of death in the intensive care unit in 170 patients with acute respiratory distress syndrome (ARDS) as a function of the number of high-risk tertiles: age $>62 \mathrm{y}$, plateau pressure $>29 \mathrm{~cm} \mathrm{H} \mathrm{H}_{2} \mathrm{O}$, and $\mathrm{P}_{\mathrm{aO}_{2}} / \mathrm{F}_{\mathrm{IO}_{2}}<112 \mathrm{~mm} \mathrm{Hg}$, at the time of meeting the American-European Consensus Conference definition of acute respiratory distress syndrome. The error bars denote the $95 \%$ confidence intervals (see text for details). $R R=$ relative risk.

Using Monte-Carlo simulation, the chi-square statistic computed for each data set validated the statistical significance of the 3 risk factors (age plus $\mathrm{P}_{\text {plat }}$ plus $\mathrm{P}_{\mathrm{aO}_{2}} / \mathrm{F}_{\mathrm{IO}_{2}}$ ) with similar statistical significance $(P<.001)$. External validation of our model to the low- $\mathrm{V}_{\mathrm{T}}$ group from the ARIES trial $(n=50)^{18}$ showed good performance for our model. Table 4 describes the validation cohort. Overall ICU mortality was $32 \%$ (Table 5). When the highest-risk values from the derivation cohort were examined in the validation population, we found that the 11 patients with no highest-risk tertiles had a mortality of $0 \%$. The 26 patients with only one highest-risk tertile had a mortality of 27\%. The 9 patients with 2 highest-risk tertiles had a $56 \%$ mortality. And the 4 patients with all 3 highest-risk tertiles had $100 \%$ mortality $(P<.001)$.

When we compared the receiver operating characteristic curve for the model in the derivation and validation cohorts to the APACHE II scores, our tertile model outperformed APACHE II (Fig. 2). The area under the curve for the tertiles model in the derivation data set was 0.725 , compared to 0.695 for APACHE II. For the validation cohort the area under the curve for the model was 0.810 , whereas the area under the curve for APACHE II was $0.620(P<.001)$.

\section{Discussion}

Our main finding is that our prediction model based on tertiles of age, $\mathrm{P}_{\text {plat }}$, and $\mathrm{P}_{\mathrm{aO}} / \mathrm{F}_{\mathrm{IO}_{2}}$ at the time patients ventilated with a lung-protective ventilation strategy met American-European Consensus Conference ARDS criteria, identifies patients with the lowest and highest risk of ICU death. The present study is the first to explore ARDS
Table 4. Validation Cohort*

\begin{tabular}{|c|c|}
\hline Male, no. (\%) & $23(40)$ \\
\hline Age $(y)$ & $48 \pm 18$ \\
\hline \multicolumn{2}{|l|}{ Main Diagnosis, no. (\%) } \\
\hline Sepsis & $14(28)$ \\
\hline Pneumonia & $16(32)$ \\
\hline Multiple trauma & $11(22)$ \\
\hline Aspiration & $4(8)$ \\
\hline \multicolumn{2}{|l|}{ Disease Severity } \\
\hline APACHE II & $18 \pm 7$ \\
\hline Lung Injury Severity Score & $2.9 \pm 0,4$ \\
\hline Days in ICU before meeting ARDS criteria & $2.6 \pm 0.4$ \\
\hline \multicolumn{2}{|l|}{ Physiologic Variables } \\
\hline $\mathrm{pH}$ & $7.36 \pm 0.05$ \\
\hline $\mathrm{P}_{\mathrm{aCO}_{2}}(\mathrm{~mm} \mathrm{Hg})$ & $40 \pm 6$ \\
\hline $\mathrm{P}_{\mathrm{aO}_{2}} / \mathrm{F}_{\mathrm{IO}_{2}}(\mathrm{~mm} \mathrm{Hg})$ & $124 \pm 34$ \\
\hline \multicolumn{2}{|l|}{ Ventilation Variables } \\
\hline $\mathrm{V}_{\mathrm{T}}(\mathrm{mL} / \mathrm{kg}$ predicted body weight $)$ & $9.9 \pm 0.5$ \\
\hline $\mathrm{F}_{\mathrm{IO}_{2}}$ & $0.65 \pm 0.20$ \\
\hline Respiratory rate (breaths/min) & $15 \pm 2$ \\
\hline $\operatorname{PEEP}\left(\mathrm{cm} \mathrm{H}_{2} \mathrm{O}\right)$ & $8 \pm 3$ \\
\hline Plateau airway pressure $\left(\mathrm{cm} \mathrm{H}_{2} \mathrm{O}\right)$ & $32 \pm 6$ \\
\hline Number of organ failures & $0.8 \pm 0.9$ \\
\hline \multicolumn{2}{|c|}{$\begin{array}{l}\text { * } 50 \text { intensive care unit (ICU) patients with persistent ARDS: measurements taken at the time } \\
\text { the patients met the American-European Consensus Conference definition of acute } \\
\text { respiratory distress syndrome (ARDS). } \\
\pm \text { values are mean } \pm \mathrm{SD}\end{array}$} \\
\hline
\end{tabular}

Table 5. Validation Cohort Mortality

\begin{tabular}{lcc}
\hline \hline $\begin{array}{c}\text { Number of } \\
\text { Highest-Risk Tertiles }\end{array}$ & $\begin{array}{c}\text { Patients } \\
(\mathrm{n})\end{array}$ & $\begin{array}{c}\text { Mortality* } \\
(\%)\end{array}$ \\
\hline None & 11 & 0 \\
1 & 26 & 27 \\
2 & 9 & 56 \\
3 & 4 & 100
\end{tabular}

* Mortality is represented as a function of the number of any combination of high risk tertiles for age $\left(>62\right.$ y), plateau airway pressure $\left(>29 \mathrm{~cm} \mathrm{H}_{2} \mathrm{O}\right)$, and $\mathrm{P}_{\mathrm{aO}_{2}} / \mathrm{F}_{\mathrm{IO}_{2}}$ ratio $(<112$ $\mathrm{mmHg})$ at study entry. $(P<.001)$.

mortality prediction based on tertiles of respiratory and ventilation variables. Risk stratification using tertiles is a common practice in the endocrine and cardiovascular literature. ${ }^{27-30}$ By evaluating physiological variables and biomarkers involved in the development and progression of several disease states, those studies revealed that tertile stratification can predict a profile associated with the greatest or the lowest risk for a selected outcome. Tertiles allow expression of clinical values in ordinal range categories, akin to how clinicians routinely categorize patients into risk groups. In our study, tertile categorization of certain variables detected useful information about the overall population that may not be as evident when evaluating the 

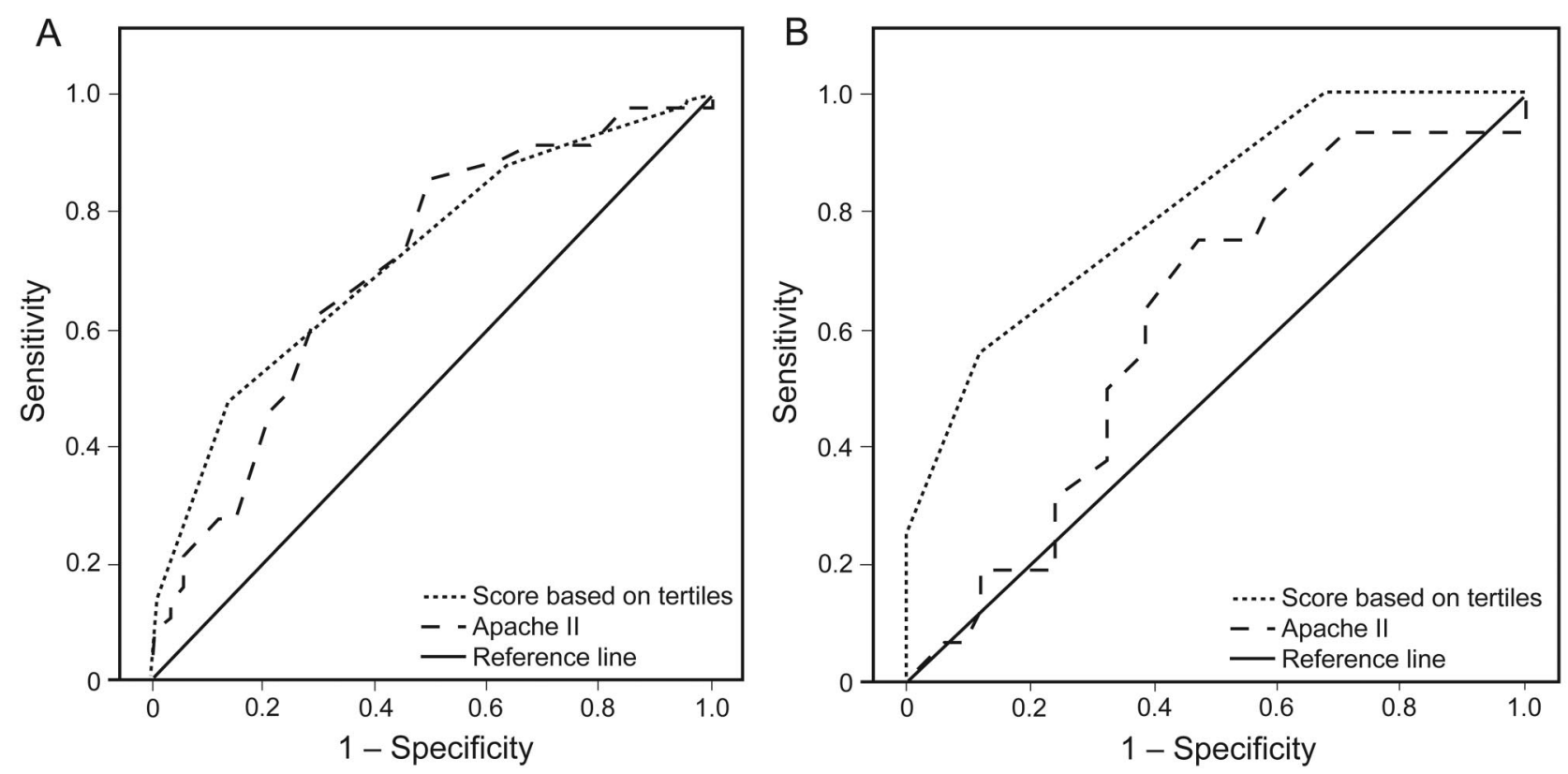

Fig. 2. Receiver operating characteristic curves for our tertiles model versus Acute Physiology and Chronic Health Evaluation (APACHE II) score. A: Derivation cohort: area under the curve 0.725 for the tertiles model, versus 0.695 for APACHE II. B: Validation cohort: area under the curve 0.810 for the tertiles model, versus 0.620 for APACHE II.

mean values of those variables. Tertile categorization could have several benefits. First, patients in the highest-risk tertile may warrant closer clinical attention to improve outcomes. On the other hand, tertiles might identify patients in whom benefit from treatment may be limited or disproportional to the resources used. Some interventions may have greater benefits in patients with moderate disease severity (middle tertile). Second, the identification of ARDS patients in the lowest-risk tertile could permit substantial cost savings in hospital days, through appropriate and efficient discharge planning.

The major 3 reasons substantiating the use of tertiles are:

- Simplicity: Tertiles are easy to apply at the bedside.

- Stability: Tertiles have been compared to other percentiles of the distribution studied, and the high-risk tertile is near the center of a stable plateau-shaped significance maximum.

- Reasonable Group Size: The number of patients with the maximum score (clinical values at ARDS onset in all 3 high-risk tertiles) was about $6 \%$ in our study. This is above the expected $1 / 27$ proportion expected for the upper tertiles of 3 independent variables, since all of our variables are predictors of severity: they are not independent.

In most epidemiological studies that have used the American-European Consensus Conference ALI and ARDS definitions, ${ }^{2-5,7-11}$ age, the underlying medical condition, degree of lung damage, extrapulmonary organ dysfunction, and ongoing sepsis are the most commonly reported pre- dictors of mortality. In general, outcome is worse with increasing age. ${ }^{31}$ Patients with more severe lung disease tend to have lower $\mathrm{P}_{\mathrm{aO}_{2}} / \mathrm{F}_{\mathrm{IO}_{2}}$. One of the most interesting of our findings is the importance of the initial $\mathrm{P}_{\mathrm{aO}_{2}} / \mathrm{F}_{\mathrm{IO}_{2}}$ (at the time of ARDS diagnosis) as a survival predictor in ARDS patients, independent of the underlying disease. In our 2 independent ARDS populations, the mean $\mathrm{P}_{\mathrm{aO}_{2}} / \mathrm{F}_{\mathrm{IO}_{2}}$ at study entry was similar in ICU survivors and non-survivors. However, by stratifying $\mathrm{P}_{\mathrm{aO}} / \mathrm{F}_{\mathrm{IO}_{2}}$ in tertiles, the tertile of $\mathrm{P}_{\mathrm{aO}} / \mathrm{F}_{\mathrm{IO}_{2}}<112 \mathrm{~mm} \mathrm{Hg}$ identified patients with an absolute mortality that was almost double that of the other 2 tertiles combined ( $47 \%$ vs $25 \%, P<.001$ ). We think that this subgroup of patients should be the target of extraordinary measures in clinical trials aimed to decrease ARDS mortality. This speculation is supported by the results of 2 recent large systematic reviews/meta-analyses of clinical trials in patients with ALI/ARDS that evaluated the survival impact of prone positioning ${ }^{32}$ and high PEEP. ${ }^{33}$ Prone positioning and high PEEP were associated with significantly improved survival only in the subgroup of patients with the lowest $\mathrm{P}_{\mathrm{aO}} / \mathrm{F}_{\mathrm{IO}_{2}}$ range.

One third of our derivation population had an initial $\mathrm{P}_{\text {plat }}>29 \mathrm{~cm} \mathrm{H}_{2} \mathrm{O}$. Note that the initial mean $\mathrm{V}_{\mathrm{T}}$ (data not shown in the tables) in each of the $\mathrm{P}_{\text {plat }}$ tertiles did not differ $(7.5 \pm 1.8 \mathrm{~mL} / \mathrm{kg}, 7.7 \pm 1.4 \mathrm{~mL} / \mathrm{kg}$, and $7.8 \pm 1.7 \mathrm{~mL} / \mathrm{kg}$ for the low, middle, and high tertiles, respectively, $P=.62$ ). It is well established that there is a direct relationship between $\mathrm{P}_{\text {plat }}$ and mortality. ${ }^{34-37}$ In many epidemiological studies that used the American-European 
Consensus Conference ALI and ARDS definitions $2-5,7-11$ the impact on outcome of $\mathrm{V}_{\mathrm{T}}$ or $\mathrm{P}_{\text {plat }}$ was not evaluated. In most of those studies the patients were treated with $\mathrm{V}_{\mathrm{T}}$ above the current recommendation. In a recent secondary analysis of patients with ALI, screened during 1999-2000, Cooke et $\mathrm{al}^{11}$ found that the mortality predictors were similar to those in the general population of critically ill patients. Variables that predicted mortality were age, nonpulmonary organ dysfunction, history of leukemia and hepatic or congestive heart failure, arterial $\mathrm{pH}$, ICU stay prior to ALI onset, minute ventilation, and $\mathrm{P}_{\mathrm{aCO}}$. Our study did not fully reproduce those findings; only mean age and ICU stay prior to ARDS onset were significantly different in survivors versus non-survivors.

It is important to emphasize that our data, in both the derivation cohort (patients from the HELP study) ${ }^{17}$ and the validation cohort (patients from the ARIES treatment arm), ${ }^{18}$ were from the time the patients met the American-European Consensus Conference ARDS definition, ${ }^{15}$ and the patients were subsequently ventilated with a lung-protective ventilation strategy, so we cannot expect this model to hold for patients ventilated in a non-lung-protective manner. It is quite clear that large $\mathrm{V}_{\mathrm{T}}$ and high $\mathrm{P}_{\text {plat }}$ cause ventilator-induced lung injury on top of the preexisting ARDS, and we do not expect our model to predict outcomes in that setting.

It is also important that $\mathrm{P}_{\text {plat }}$ be measured during a passive inspiration followed by an end-inspiratory pause of sufficient duration to allow the pressure to plateau. We do expect our model to apply to all patients with ARDS, regardless of etiology or comorbidities. The prediction model was developed from 170 patients in the HELP study, ${ }^{17}$ which had no exclusion criteria: all patients, regardless of ARDS etiology or prognosis were included.

\section{Limitations}

Because of several study limitations our findings must be considered preliminary and exploratory. First, although our model showed external validity with an independent group of ARDS patients, our validation cohort sample was relatively small. Second, additional variables that influence ICU outcome may be identified in further derivation cohorts. Third, continuous multivariate methods may be more practical in cases where variables have intricate dependencies and associations with outcome that might not be correctly represented by tertiles; however, we have no reason to believe that this is applicable to the variables we studied.

Our study has several strengths. First, our study design included all consecutive patients who met the ARDS criteria, except patients with brain death, terminal-stage cancer, or a do-not-resuscitate order, so we believe that our patients closely represented routine ARDS patients. Second, patients were in a multidisciplinary network of teaching hospitals, not just one institution. Third, we validated our model with an independent cohort of patients with established ARDS. Fourth, our prediction model combines variables of potentially modifiable severity $\left(\mathrm{P}_{\mathrm{aO}_{2}} / \mathrm{F}_{\mathrm{IO}_{2}}\right.$ and $\left.\mathrm{P}_{\text {plat }}\right)$ and a non-modifiable risk factor (age) that are readily measured at the bedside. Finally, our tertiles model outperformed APACHE II in predicting mortality. APACHE II is a composite score developed to assess the risk of hospital death across a spectrum of illnesses rather than for a particular disease process such as ARDS. However, our approach must be further validated with other ARDS populations and by other groups. Clearly, our a posteriori selection of patients from our own previous studies may have biased our results in some unknown way. Regardless of whether the values in the high-risk tertiles are associated with higher mortality, the differences in care (ventilation and oxygenation) require further investigation. Since our study was observational and we did not exclude any patients during the study period, we are aware that patient characteristics influence physicians' treatment decisions and could be important in guiding future studies. The measure of potential confounders that might influence both survival and care decisions is beyond the scope of the present study. We do not know whether the treatmentdependent variables $\left(\mathrm{P}_{\mathrm{aO}_{2}} / \mathrm{F}_{\mathrm{IO}_{2}}\right.$ and $\left.\mathrm{P}_{\text {plat }}\right)$ will influence the performance of our model under different practice patterns. We acknowledge that our results apply only to a prescribed set of circumstances. If circumstances change (eg, a novel method of oxygenation/ventilation or a new therapy for severe sepsis), the distribution may differ.

\section{Conclusions}

The use of tertile stratification for age, $\mathrm{P}_{\text {plat }}$, and $\mathrm{P}_{\mathrm{aO}_{2}}$ ' $\mathrm{F}_{\mathrm{IO}_{2}}$ at the time patients meet ARDS criteria can identify patients who are at greatest risk of death in the ICU. This model should be further assessed in future studies.

\section{REFERENCES}

1. Monchi M, Bellenfant F, Cariou A, Joly LM, Thebert D, Laurent I, et al. Early predictive factors of survival in the acute respiratory distress syndrome: a multivariate analysis. Am J Respir Crit Care Med 1998;158(4):1076-1081.

2. Estenssoro E, Dubin A, Laffaire E, Canales H, Saenz G, Moseinco M, et al. Incidence, clinical course, and outcome in 217 patients with acute respiratory distress syndrome. Crit Care Med 2002;30(11):2450-2456.

3. Brun-Buisson C, Minelli C, Bertolini G, Brazzi L, Pimentel J, Lewandowski K, et al; ALIVE Study Group. Epidemiology and outcome of acute lung injury in European intensive care units: results from the ALIVE study. Intensive Care Med 2004;30(1):51-61.

4. Gong MN, Thompson BT, Williams P, Pothier L, Boyce PD, Christiani DC. Clinical predictors of and mortality in acute respiratory distress syndrome: potential role of red cell transfusion. Crit Care Med 2005;33(6):1191-1198.

5. Rubenfeld GD, Caldwell E, Peabody E, Weaver J, Martin DP, Neff $\mathrm{M}$, et al. Incidence and outcomes of acute lung injury. N Engl J Med 2005;353(16):1685-1693. 
6. Ware JH. The limitations of risk factors as prognostic tools. N Engl J Med 2006;355(25):2615-2617.

7. Zilberberg MD, Epstein SK. Acute lung injury in the medical ICU: comorbid conditions, age, etiology, and hospital outcome. Am J Respir Crit Care Med 1998;157(4):1159-1164.

8. Luhr OR, Karlsson M, Thorsteinsson A, Rylander C, Frostell CG. The impact of respiratory variables on mortality in non-ARDS and ARDS patients requiring mechanical ventilation. Intensive Care Med 2000;26(5):508-517.

9. Navarrete-Navarro P, Ruis-Bailen M, Rivera-Fernandez R, Guerrero-Lopez F, Dolores M, Gallego de Guzman P, Vazquez-Mata G. Acute respiratory distress syndrome in trauma patients: ICU mortality and prediction factors. Intensive Care Med 2000;26(11):1624-1629.

10. Moran JL, Solomon PJ, Fox V, Salagaras M, Williams PJ, Quinlan $\mathrm{K}$, Bersten AD. Modeling 30-day mortality in the Acute Respiratory Distress Syndrome (ARDS) in an adult ICU. Anaesth Intensive Care 2004;32(3):317-329.

11. Cooke CR, Kahn JM, Caldwell E, Okamoto VN, Heckbert SR, Hudson LD, Rubenfeld GD. Predictors of hospital mortality in a population-based cohort of patients with acute lung injury. Crit Care Med 2008;36(5):1412-1420.

12. Hudson LD, Milberg JA, Anardi D, Maunder RJ. Clinical risks for development of the acute respiratory distress syndrome. Am J Respir Crit Care Med 1995;151(2):293-301.

13. Kraft P, Fridrich P, Pernerstorfer T, Fitzgerald RD, Koc D, Schneider $\mathrm{B}$, et al. The acute respiratory distress syndrome: definitions, severity and clinical outcome: an analysis of 101 clinical investigations. Intensive Care Med 1996;22(6):519-529.

14. Squara P, Dhainaut JFA, Artigas A, Carlet J; the European Collaborative ARDS Working Group. Hemodynamic profile in severe ARDS: results of the European Collaborative ARDS study. Intensive Care Med 1998;24(10):1018-1028.

15. Bernard GR, Artigas A, Brigham KL, Carlet J, Falke K, Hudson LD, et al. The American-European Consensus Conference on ARDS: definitions, mechanisms, relevant outcome, and critical trial coordination. Am J Respir Crit Care Med 1994;149(3):818-824.

16. Kirsch I, Deacon BJ, Huedo-Medina TB, Scoboria A, Moore TJ, Johnson BT. Initial severity and antidepressant benefits: a metaanalysis of data submitted to the Food and Drug Administration. PLoS Medicine 2008;5(2):e45.

17. Villar J, Pérez-Méndez L, López J, Belda J, Blanco J, Saralegui I, et $\mathrm{al}$; the HELP Network. An early PEEP/ $/ \mathrm{F}_{2}$ trial identifies different degrees of lung injury in patients with acute respiratory distress syndrome. Am J Respir Crit Care Med 2007;176(8):795-804.

18. Villar J, Kacmarek RM, Pérez-Méndez L, Aguirre-Jaime A; the ARIES Network. A high PEEP, low tidal volume ventilatory strategy improves outcome in persistent acute respiratory distress syndrome: a randomized controlled trial. Crit Care Med 2006;34(5):1311-1318.

19. Knaus WA, Draper EA, Wagner DP, Zimmerman JE. APACHE II: a severity of disease classification system. Crit Care Med 1985; 13(10):818-829.

20. Murray JE, Matthay MA, Luce JM, Flick MR. An expanded definition of the adult respiratory distress syndrome. Am Rev Respir Dis 1988;138(3):720-723.
21. Vincent JL, de Mendonça A, Cantraine F, Moreno R, Takala J, Suter $\mathrm{PM}$, et al. Use of the SOFA score to assess the incidence of organ dysfunction/failure in intensive care units: results of a multicenter, prospective study. Crit Care Med 1998;26(11):1793-1800.

22. Lunneborg CE. Data analysis by resampling: concepts and applications. Pacific Grove, CA: Duxbury Press; 2000.

23. Good PI. Permutation, parametric and bootstrap tests of hypotheses, 3rd edition. New York: Springer-Verlag; 2005.

24. Bishop YMM, Fienberg SE, Holland PW. discrete multivariate analysis: theory and practice. Cambridge: M.I.T. Press; 1975.

25. Fienberg SE. The analysis of cross-classified categorical data. Cambridge: M.I.T. Press; 1977

26. Zweig MH, Campbell G. Receiver-operating characteristic (ROC) plots: a fundamental evaluation tool in clinical medicine. Clin Chem 1993;39(4):561-577

27. Laaksonen DE, Niskanen L, Nyyssönen K, Punnonen K, Tuomainen TP, Salonen JT. C-reactive protein in the prediction of cardiovascular and overall mortality in middle-age men: a population-based cohort study. Eur Heart J 2005;26(17):1783-1789.

28. Nam BH, Kannel WB, D'Agostino RB. Search for an optimal atherogenic lipid risk profile: from the Framingham Study. Am J Cardiol 2006;97(3):372-375.

29. Störk S, Feelders RA, van den Beld AW, Steyerberg EW, Savelkoul HFJ, Lamberts SWJ, et al. Prediction of mortality risk in the elderly. Am J Med 2006;119(6):519-525.

30. Onat A, Can G, Hergenç G, Yazici M, Karabulut A, Albayrak S. Serum apolipoprotein B predicts dyslipemia, metabolic syndrome and, in women, hypertension and diabetes, independent of markers of central obesity and inflammation. Int J Obes 2007;31(7):1119-1125.

31. Gee MH, Gottlieb JI, Albertine KH, Kubis JM, Peters SP, Fish JE Physiology of aging related to outcome in the adult respiratory distress syndrome. J Appl Physiol 1990;69(3):822-829.

32. Sud S, Friedrich JO, Taccone P, Polli F, Adhikari NK, Latini R, et al. Prone ventilation reduces mortality in patients with acute respiratory failure and severe hypoxemia: systematic review and metaanalysis. Intensive Care Med 2010;36(4)585-599.

33. Briel M, Meade M, Mercat A, Brower RG, Talmor D, Walter SD, et al. Higher vs lower PEEP in patients with acute lung injury and acute respiratory distress syndrome: systematic review and meta-analysis. JAMA 2010;303(9):865-873.

34. Hager DN, Krishnan JA, Hayden DL, Brower RG. Tidal volume reduction in patients with acute lung injury when plateau pressures are not high. Am J Respir Crit Care Med 2005;172(10):1241-1245.

35. Checkley W, Brower R, Korpak A, Thompson BT; the Acute Respiratory Distress Syndrome investigators. Effects of a clinical trial on mechanical ventilation practices in patients with acute lung injury. Am J Respir Crit Care Med 2008;177(11):1215-1222.

36. The Acute Respiratory Distress Syndrome Network. Ventilation with lower tidal volumes as compared with traditional tidal volumes for acute lung injury and the acute respiratory distress syndrome. N Engl J Med 2000;342(18):1301-1308.

37. Shiu KK, Rosen MJ. Is there a safe plateau pressure threshold for patients with acute lung injury and acute respiratory distress syndrome? Am J Respir Crit Care Med 2006;173(6):686.

This article is approved for Continuing Respiratory Care Education credit. For information and to obtain your CRCE

(free to AARC members) visit

RCJournal.com

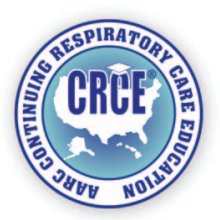

